\title{
REPRESENTACIONES DE LO MONSTRUOSO EN EL SUUWÕ', TRADICIÓN ORAL BRIBRI
}

\author{
Carla Victoria Jara Murillo
}

\section{(c) $(7)(9)$}

Esta obra está bajo una licencia Creative Commons 



\title{
REPRESENTACIONES DE LO MONSTRUOSO EN EL SUUUO', TRADICIÓN ORAL BRIBRI
}

\author{
REPRESENTATIONS OF MONSTROSITY IN THE SŨUÕ' ORAL \\ BRIBRI TRADITION
}

\begin{abstract}
RESUMEN
En este trabajo se describe el concepto de sũwõ', código de comportamientos que Sibö, el dios de los bribris, dejó a este pueblo indígena y que se transmite mediante la tradición oral. En ese marco, se aborda la temática de los seres mitológicos, dentro de los cuales se encuentran los bë́ 'diablos y otras entidades nocivas'. Los íyiwak sulùsi, monstruos que castigan el incesto, pertenecen a ese grupo. Se ejemplifica la representación de lo monstruoso en esta tradición oral a partir de estos seres mitológicos.

Palabras clave: pueblo bribri de Costa Rica, mitología bribri, tradición oral bribri, incesto, monstruosidad en literatura.
\end{abstract}

\begin{abstract}
In this paper the concept of sũwõ' is described as the code of behavior that Sibö̀, god of the Bribri people, left to them to be transmitted by oral tradition. In this context, the topic of mythological beings such as bë' 'devils and other harmful beings' is addressed. The íyiwak sulùsi, monsters in charge of punishing incest, belong to that group. The representation of monstrosity in this oral tradition is exemplified on the basis of these mythological beings.

Key words: Bribri people from Costa Rica, Bribri mythology, Bribri oral tradition, incest, monstrosity in literature.
\end{abstract}

\section{El pueblo bribri}

Los bribris son un pueblo originario de la Cordillera de Talamanca, la cual se ubica en el sureste de Costa Rica y se prolonga por el territorio panameño con el nombre de Cordillera Central. Es el grupo más numeroso de Costa Rica según el Censo Nacional de 2011 (INEC, 2013). En territorios indígenas bribris residen cerca de 13000 personas, de las cuales unas 9000 habitan

Dra. Carla Victoria Jara Murillo. Universidad de Costa Rica. Profesora de la Escuela de Filología, Lingüística y Literatura. Costa Rica.

Correo electrónico: carla.jara@ucr.ac.cr

Recepción: 17- 02- 2015

Aceptación: 19- 06- 2015 
en los territorios Talamanca Bribri y Kéköldi, ubicados en la vertiente atlántica de la cordillera, y unas 4000, en los territorios de Salite y Cabagra, en la vertiente pacífica. Según el Censo, solo el 55\% de la población reporta el bribri, lengua de filiación chibcha, como su idioma materno, lo que muestra que esta lengua se suma a las miles de lenguas del mundo en peligro de extinción. El Atlas de las lenguas del mundo en peligro de UNESCO (Moseley, 2010) la califica como lengua en estado vulnerable; sin embargo, el riguroso estudio sobre el estado de conservación de las lenguas de Costa Rica de Sánchez-Avendaño (2013) demuestra que el nivel de riesgo en que se encuentra el bribri es mucho mayor. De continuar esta tendencia, también su rica tradición oral se verá disminuida, por lo que es fundamental que en actividades académicas dedicadas al análisis literario se incluyan muestras y análisis de su literatura oral, tanto en su versión original en bribri como en sus traducciones al español.

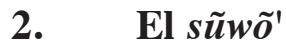

Para abordar la visión de mundo bribri, partimos del concepto fundamental del sũwõ' (o sũwã', según el dialecto). La palabra misma tiene una compleja esfera semántica, ya que puede significar historia, alma, aire, viento. El sũwõ' es, en esencia, el cuerpo de conocimiento que define la forma en que los bribris interpretan la realidad.

Las narrativas y descripciones que lo componen fluyen entre dos mundos discursivos: el mundo de Sibồ, al que llamamos "mundo mitológico", es la representación de los hechos en una dimensión abstracta y sobrenatural; su función es aportar la "causa creativa" del otro mundo, el concreto y real de los bribris, al que denominamos "mundo actual". Ambos mundos discursivos se yuxtaponen reflejando un sistema de creencias causalista en el cual todo lo que existe en el mundo actual tiene su razón de ser en el mundo mitológico. Por ello, el sũwõ' no solo contiene la narrativa referida al mundo de Sibồ, sino también los códigos de comportamiento para la vida en general, que se derivan y explican por medio de lo que él hizo antes de crear la semilla de maíz origen de los indígenas: cómo vivió, cómo organizó el mundo en que vivimos.

Los dos mundos discursivos se encuentran en una relación que hemos llamado “especular inversa”, relación que se da en tres planos: espacial, temporal y ontológico.

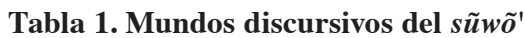

\begin{tabular}{|l|l|l|}
\hline MUNDOS & MITOLÓGICO (de Sibö) & ACTUAL (de los bribris) \\
\hline Plano espacial & subterráneo & superficial \\
\hline Plano temporal & tiempo de la oscuridad & tiempo de la luz \\
\hline Plano ontológico & pequeño/grande & grande/pequeño \\
\hline Ejemplo & Áksula (enorme) & comején (pequeño) \\
\hline
\end{tabular}

Según se esquematiza en la Tabla 1, en términos de espacio, el mundo mitológico se ubica en el plano subterráneo y el mundo actual se ubica en el plano de la superficie. En cuanto al tiempo, existen el tiempo de la oscuridad en el mundo mitológico y el tiempo de la luz, en el mundo actual.

Todos estos planos coexisten: los mundos son uno reflejo del otro, solo que el mundo mitológico es invisible (cp. Jara-Murillo y García-Segura, 1997). Esta imbricación de tiempo y espacio se manifiesta en el hecho de que una misma palabra kấ (o kố, según el dialecto) significa a la vez 'tiempo' y 'lugar'. 
Desde el punto de vista ontológico, todo ser del mundo en el que estamos tiene un ser correspondiente en el otro mundo. Los seres mitológicos existen en el mundo de Sibö̀ y proyectan una imagen de sí mismos en el mundo actual. En esta relación encontramos de nuevo una organización de tipo imagen invertida, según la cual lo que es pequeño en este mundo es grande en el otro y viceversa. Así por ejemplo, García-Segura y Jaén (1996, p. 77) reportan que a Áksula, el rey del comején, en este mundo lo vemos pequeño, pero en el otro mundo es un ser gigantesco. Así sucede también con los monstruos que castigan el incesto.

Lo que muestran las correspondencias o relaciones especulares en los planos espacial, temporal y ontológico es que la visión de mundo bribri está constituida por una interpretación armónica de la naturaleza en todas sus facetas: tiempo, espacio y ser.

\section{Los monstruos que castigan el incesto en el contexto del sũwõ'}

Con el objetivo de comprender mejor el complejo mundo del sũwõ', en el Diccionario de mitología bribri (Jara-Murillo y García-Segura, 2003) se propone una "agrupación tentativa" de entidades que permite observar con mayor facilidad las relaciones entre ellas. Ahí se proponen las siguientes categorías de seres:

0. Sibö: Dios o héroe cultural.

1. Yàmipa: Personajes principales, parientes y colaboradores de Sibö.

2. Akéköl: Máximos representantes de las plantas y los animales.

3. Bë: Diablos y otras entidades malignas. Este grupo incluye: humanidades anteriores a se' ditsồ 'nuestra semilla'; diablos; espantos; monstruos que castigan el incesto; otros seres que castigan por otras razones; señales de mal agüero, tabúes, enfermedades y calamidades.

4. Ditsồ: Semilla de maíz origen de los indígenas.

5. Íyi: Cosas. Incluye: piedras mágicas, curativas y sagradas, y otros objetos míticos sagrados.

6. Kã́ / kố: Lugares. Incluye: ríos, quebradas, montañas, cerros...

Figura 1. Entidades del $s \tilde{u} w \tilde{\sigma}^{\prime}$

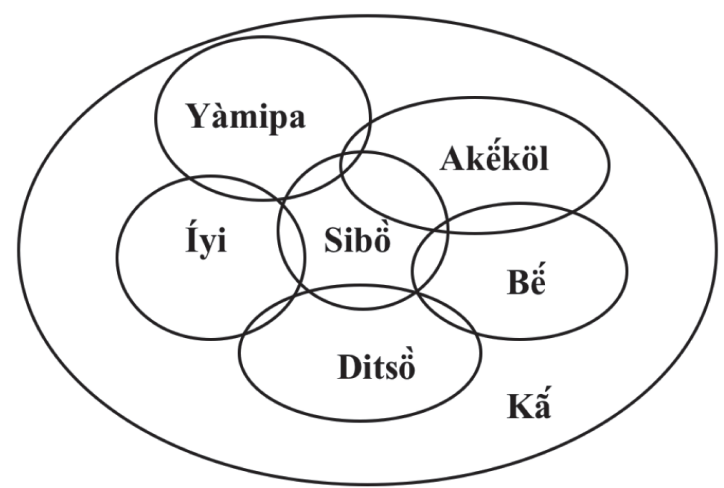

Fuente: Diccionario de mitología bribri (Jara-Murillo y García-Segura, 2003) 


\section{4. ¿Quiénes cometen incesto?: El sistema de parentesco bribri}

Se hace imprescindible, antes de entrar propiamente a encontrarnos con los monstruos, comprender quiénes cometen incesto, de acuerdo con el sistema de parentesco bribri. Haré una referencia muy breve sobre el que es un sistema de parentesco muy complejo.

En primer lugar, los bribris se organizan en clanes cuyo parentesco se traza por vía de la madre, por lo cual es un sistema de parentesco matrilineal. Estrictamente hablando, cualquier relación sexual con un miembro del propio clan es incestuosa. También son incestuosas las relaciones con el padre y los tíos paternos, aunque estos no pertenecen al mismo clan del ego.

En cuanto a los familiares de la generación del ego, los bribris distinguen entre primos paralelos y primos cruzados, y esta diferencia es fundamental para comprender no solo quiénes cometen incesto, sino también quién es la pareja ideal.

Los primos paralelos son los hijos de las tías maternas y de los tíos paternos del ego. Estos primos son considerados lo mismo que hermanos, lo que queda demostrado por medio de los términos con que se designan:

Tabla 2. Terminología de parentesco de la generación del ego

\begin{tabular}{|l|l|l|}
\hline él & $\begin{array}{l}\text { hermano }(a) \text { y primo }(a) \text { paralelo }(a) \\
\text { del mismo sexo }\end{array}$ & $\begin{array}{l}\text { Primos paralelos: Hijos e hijas } \\
\text { de las tías maternas y de los tíos } \\
\text { paternos. }\end{array}$ \\
\cline { 1 - 2 } kutà & $\begin{array}{l}\text { hermana y prima paralela de } \\
\text { hombre }\end{array}$ & hermano y primo paralelo de mujer
\end{tabular}

Por lo tanto, es tan incestuosa una relación sexual con los hermanos como con los primos paralelos.

Por otra parte, los primos cruzados, que son los hijos de las tías paternas y de los tíos maternos, constituyen la pareja ideal y se designan con un único término: dawö'. Por ello, como veremos en la historia, cuando el narrador menciona que Sibồ dejó establecido quiénes serían nuestras “parejas”, utiliza para estas el término dawö'pa 'primos cruzados'.

\section{5. Ílyiwak sulùsi ena kũlǜ: Monstruos e incesto}

Para ejemplificar la representación de la monstruosidad en el sũwõ' hemos escogido una historia publicada por Francisco Pereira Mora, bribri de Amubre, Talamanca, fallecido en 1990, quien ha sido considerado un narrador de excepcionales cualidades (ConstenlaUmaña, comunicación personal). El texto Kũlũ̃ 'Incesto' (Pereira-Mora, s.f. [1983]) es el que con mayor detalle "documenta" los monstruos que castigaban el incesto.

Estos monstruos reciben en el texto la denominación de íyiwak sulùsi, literalmente: 'animales dañinos o ponzoñosos'. Pereira, en su traducción al español, los llama "bichos malos"; sin embargo, como se verá, sus cualidades permiten categorizarlos mejor como monstruos que como simples "bichos". Su rasgo contrastivo, con respecto a los "bichos" correspondientes en el mundo actual de los bribris, es su enormidad, pues como ya mencionamos, a los seres en este mundo los vemos pequeños, pero en el mundo de Sibồ son seres gigantescos. 
Comentamos antes que en el sũwõ' se manifiesta un principio de armonía en los planos temporal, espacial y ontológico. Con respecto al castigo por incesto, existe además un principio de proporcionalidad, que no se da necesariamente en todos los sistemas de creencias que conocemos. A manera de ejemplo, en nuestro Código Penal, el homicidio calificado, que es el máximo delito, impone una pena de 20 a 35 años de prisión (art. 112); sin embargo, no importa el número de homicidios calificados que haya cometido una persona en una misma ocasión, o en varias, la pena de prisión será por un máximo de 50 años (art. 51).

En el sistema de creencias bribri, el máximo delito que se puede cometer es el incesto. Al referirse a la organización social de los indígenas de Talamanca, Stone (1961, p. 75) señala:

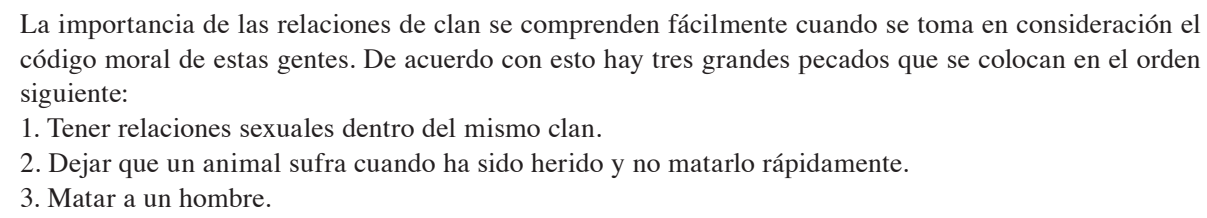

El principio de proporcionalidad al que he hecho referencia se refleja en la enormidad de los castigos establecidos en el sũwõ' en el caso de cometer incesto, tal como se verá en el texto Kũlǜ donde se detallan las características físicas de los monstruos encargados de los castigos, así como sus modi operandi.

De acuerdo con la estructura temática de la tradición oral bribri que se propone en Jara-Murillo (2006, p. 170), el texto Kũlǜ constituye una muestra bastante representativa de la manera en que se organizan los textos del sũwõ': un segmento introductorio contiene el resumen de la historia; la continuidad temática viene dada por una progresión de párrafos en cada uno de los cuales se introduce un monstruo y en el último, el castigo recibido durante el parto; deviene luego el desenlace de la historia, y un cierre o conclusión donde se establece la relación causa-efecto entre los dos mundos discursivos, el mitológico y el actual.

Tabla 3. Estructura temática del texto Kũlũ̀

\begin{tabular}{|l|l|l|}
\hline \multicolumn{1}{|l|}{ I. Resumen introductorio } & \multicolumn{2}{|l|}{} \\
\hline \multirow{5}{*}{ II. Párrafos temáticos } & DULÙ & 'la serpiente gigante' \\
\cline { 2 - 3 } & SHAKÍBÖK & 'la sanguijuela' \\
\cline { 2 - 3 } & YAWI' & 'el cangrejo' \\
\cline { 2 - 3 } & TALÓK & 'el lagarto' \\
\cline { 2 - 3 } & (resumen intermedio) \\
\cline { 2 - 3 } & KËTALI & 'el escorpión' \\
\cline { 2 - 3 } & SAKÛKICHA & 'la bejuquilla' (espía) \\
\cline { 2 - 3 } & KÖ & 'gusanitos de fuego' \\
\cline { 2 - 3 } & KÚNUK & 'partos' \\
\hline III. Desenlace & \multicolumn{2}{|l}{} \\
\hline IV. Cierre & \multicolumn{2}{|l}{} \\
\hline
\end{tabular}

Para el análisis de tal estructura, se segmentó el texto en 60 oraciones, atendiendo a la puntuación utilizada por Pereira. En la Tabla 4, cada oración aparece numerada; sin embargo, debe notarse que no se incluyen todas las oraciones (el texto original bribri se transcribe tal como fue publicado, ${ }^{1}$ la traducción es mía ${ }^{2}$ ): 
Tabla 4. Selección de oraciones del texto Kũlũ̀

\section{INTRODUCCIÓN (1-7)}

1. Mìk Sibồ dör kấ i' yö', e'tã se' ulìtãnẽ balë' tso' ie' wã "ditsồwöie".

2. E' ukö̀ kĩ ie' dör se' kằs e' balatë' "ditséwö wa", e' kũếki se' ulìtãnẽ ditséwö dör ikũẫkĩ ikũẫkĩ.

4. E'tã icha Sibồ dör i yë'at tö se' ulìtãnẽ kẫwotã sềnúkkwa wế sa "dawö'pa" e' tã.

5. Erë kấmĩ ë tã se' ến-ã Sibồ ujtồ e' chëwa, e'tã ñễ̃ icha tãî̃ë ie'pa ẽ' kâkã íyi sulúsi wámbalök, dồ icha "kũlừbalớkkã" ãñ̃ì tã ẽnã i kaléapa tã.

7. Kắ diö́shẽt Sibồ wã íyiwak sulúsi mãnềtẽ, kầs se' wế dör íyi sulúsi e' wámbalèkẽ ése cástigawâie (ppökörie).

DULÙ 'la serpiente' (8-19)

8. Ês icha êtöm "dulù" apàtkë' irir sa katö́k.

9. E' dör icha tkabề ês erë i wák bềrie, e' akálök dör tkềtöm $\mathrm{e}^{\prime}$ wa irir se' kalồwềkẽ.

10. Mî̀k irir icha sa kalöwềwã, tã sa dà apà atarrèwã irir i akálök ñẽ wa darểrêeë kề tî̃nấĩã éjkë.

11. E' ukö̀kĩ icha i ẽ' dawâkã shkễë, e' wösũk icha se' tsẫmĩkã i wã e' dök kấjkễë.

12. Sibồ kĩ i kiànã tö ằs se' wêir, e' kũếkĩ ie' kề dör se' ujtèwã bétk.

13. E'tã ñẽ̃̃ icha ẽ' se' ấrkẽ tkër:

14. "Kawềềè , $a^{\prime} r$ ya ówamãlẽ, $a$ ' $r$ ya tsấttkö, $a^{\prime}$ r ì i' ujtốwã..."

18. É $\tilde{E}^{\prime}$ dồ tkễkkĩ ñẽ̃e ù wế ã ie' wã se mî̀nẽ, $\mathrm{e}$ wéjkö ã ie' wã se' chalé êbitũ súnõ sa yàmĩpa ã.

19. Ês icha íyiwak sulúsi e' bák sa katö’k.

SHAKÍBÖK 'la sanguijuela'3 $(20-28)$

20. "Shakíbök" dör sa kata' ãñ̀ies.

21. Icha $\mathrm{e}^{\prime}$ wák ãñ̃̀̀es bểrie wềs tkabề ês, erë $\mathrm{e}$ ëtöm yík dör chakuáchakuâe e' wa ie' dör se' kalồwềkẽ se' tsĩ̀wö shẫë.

22. E' sềrkẽ icha di' ã.

23. Mî̀k se' wế wã íyi sulúsi ése wámbalềrule sa yàmî́pa tã e' mîã akuoók, e' tã ie' dàtske e' ñãlếka.

25. Wế dör i wámbalë' e' kalồwãwã ie' wã i tsî̀wö shẫë, uköö̀ĩ ie' wã i tkâkã tkër dipồ tãĩë ése shû́ shẫë i yík kĩ.

27. E' ukökĩ ñẽ̃ẽ, ie' yík ñẽ' ã ie' akà tulur e' wa ie' dör se' chakà katéwa; ukö̀kĩ ês ie' dör se' apë kûyèkẽ.

28. Ês ie' dör se' katèkẽ.
1. Cuando Sibồ creó este mundo, a todos nosotros [ $\left[\mathbf{s e}^{\prime}=\right.$ nosotros / seres humanos / gente / persona(s)] nos tenía guardados como "semilla" ("ditsồ wöie").

2. Después nos repartió en "clanes" ("ditséwö wa"), por eso todos nuestros clanes son diferentes.

4. Sibồ dejó dicho que debíamos casarnos con nuestros "primos cruzados" ("dawö'pa") [= parejas].

5. Pero con el tiempo, la gente olvidó la palabra de Sibồ y empezó a hacer cosas malas, hasta llegar a "cometer incesto" ("kũlũ̀balókkã") con sus parientes.

7. De un lugar subterráneo Sibồ trajo unos animales malignos (íyiwak sulúsi), para que castigaran a todos aquellos que estaban haciendo esas cosas malas.

8. Así pues envió a "dulù" ('serpiente mítica') a comer gente. 9. Era una culebra pero de aspecto enorme, que tenía cuatro barbas [= tentáculos] con las cuales agarraba a la persona.

10. Cuando atrapa a alguien, le rodea fuertemente el cuerpo con aquellos tentáculos hasta inmovilizarlo.

11. Después se yergue muy derecha mientras lo alza hasta muy alto.

12. Sibồ quería que la persona sufriera, por eso el bicho no la mataba inmediatamente.

13. Entonces desde allá arriba la persona gritaba:

14. "Aaayyy, bájenme, defiéndanme, maten esta cosa..." 18. Allá a los cuatro días la traía y dejaba caer el esqueleto en la puerta de la casa para que fuera visto por sus familiares.

19. Así pues ese bicho dañino estuvo comiendo gente.

20. "Shakíbök" (la "sanguijuela") también comía gente. 21. Era también enorme, como la culebra, pero esta tenía una trompa muy pegajosa con la cual agarraba a la persona por la espalda.

22. Vivía en los ríos.

23. Cuando alguien que había cometido incesto iba a bañarse, entonces llegaba por él.

25. Lo agarraba por el centro de la espalda y lo mantenía levantado sobre su trompa en medio de una laguna enorme.

27. Después, con aquella trompa, que tenía dientes, le comía la carne y luego le chupaba la sangre.

28. Así ella comía gente. 


\section{DESENLACE (56-59)}

56. Ês icha dawás tãĩe íyiwak sulúsi ñẽ' bák sa katök e' kũú́kĩ ñẽ̃e icha êtökicha êköltë akékëpa shakör tkồrö "úsêkölpa sã" i chö́k i ã tö a' dör i wö̀balówãmãlẽ sa' ã.

57. $\mathrm{E}^{\prime}$ wösũk akékëpa dör úsêkólpa apàtố tãĩe i kũếkĩ e' bata ie' pa dör i wồbalë' wãmãlẽ.

58. E' tã icha ie' pa kề dör i wồbalöpawã, ẽmã î̃̃̃̃ kề se' kũ' kấ i' kĩ.

59. Erë gracias que se' akëkëpa r i apàtkë' mĩmãlẽ kấ diốshẽt wế i mãnềtẽ ẽ' dök, $\mathrm{e}^{\prime}$ kũếkĩ ĩñẽ ñî́we tã se' kề wã íyiwak sulúsi e' sũnễĩã.

\section{CIERRE (60)}

60. Ẽmã $\mathrm{e}^{\prime}$ kũếkĩ î̃̃ẽ tã tãîê ie' pa kũlừbalồkẽ $\mathrm{i}$ yamî́pa tã, tã kề i sawànẽ ì yök; e' kû̀kû́pa ñẽ' kế ska, ẽmã kề alêë $\mathrm{i}$ wã̃ $\mathrm{i}$ wámbalềnẽ.
56. Así durante muchos años estos bichos estuvieron comieron gente y por eso un día un grupo de señores decidió ir "adonde los úsêkölpa" (sumos sacerdotes) a pedirles que los exterminaran.

57. Los señores les pagaron mucho a los sacerdotes y por eso al final ellos accedieron.

58. Si ellos no hubieran accedido, hoy no estaríamos en este mundo.

59. Pero gracias a que nuestros señores los volvieron a mandar al mundo subterráneo de donde habían venido, por eso hoy ya no vemos a esos bichos.

60. Entonces por eso es que hoy muchas personas cometen incesto y no tienen miedo de nada; pero si fuera como en aquellos tiempos, entonces definitivamente no lo harían.

\section{Comentarios finales}

El macrogénero de la tradición oral bribri denominado sũwõ' es ante todo un código de conducta para todos los aspectos de la vida. Con la influencia avasalladora de la cultura exógena, este código está borrándose rápidamente del sistema conceptual bribri; sin embargo, el grado de avance de este desplazamiento es muy variable entre las distintas comunidades, sin que pueda decirse que se haya conservado mucho en ninguna. Prueba de ello es que ya no se forman especialistas en los distintos cargos de la organización social tradicional, a excepción quizás de algún awá 'médico'. Sobre este tema, remito al libro Cargos tradicionales del pueblo bribri: Sĩớtãmĩ, Óköm, Awá (Jara-Murillo y García-Segura, 2008).

Para concluir, quiero rescatar un texto de Juana Sánchez (Palmer et ál, 1992, pp. 43-45) en el que se muestra que el sũwõ', si bien es vestigial en la actualidad, organiza la visión de mundo de todos los bribris, incluidos los que han dejado las tierras ancestrales de Talamanca y emigraron a territorios aledaños a la costa atlántica, como es el caso de los pobladores de Kéköldi (Palmer et ál, 1992, p. 70).

En este texto, titulado "La importancia de los clanes" y publicado solo en español, la autora transmite básicamente la misma historia del Kũlũ̀ y hace un recuento de los principales castigos del incesto que hemos visto en el texto de Pereira, que era de la zona de Amubre.

En particular ella menciona "una gigantesca serpiente /chbë̀köl/" (dulù) y menciona "otro monstruo que fue similar a una sanguijuela /shikibök/". Sin embargo, el castigo que más enfatiza Sánchez es el de los partos difíciles y agrega un aspecto que no aparece en la historia de Pereira: la deformidad de los niños. También agrega otro ser que castiga el incesto, pero que no es un monstruo sino una calamidad: /bli/ 'el hambre'. El texto de Sánchez concluye así:

Ahora algunos indígenas y mestizos no quieren aceptar esta historia. Se quejan de que la vida está muy dura, y dicen que ese niño nació así porque Dios lo quiso. Muchos dicen: "Ya no les tememos a esos castigos, porque los médicos y la medicina moderna salvan a las mujeres cuando el parto es difícil. ¡Los monstruos que se comían a los indígenas! Eso fue antes, ya no volverán." 
Pero no hay que confiarse mucho, porque cuenta el señor Juan Vargas que un día, conversando con un indígena de Alto Chirripó, éste le contó que en esa reserva vivió un indígena que tenía relaciones sexuales con dos de sus hijas; que un día este hombre salió a trabajar con una de ellas y, al pasar cerca de una laguna que ahí existe, vieron una enorme serpiente que se lanzó sobre el indígena y lo devoró. Luego el animal desapareció dentro de la laguna; esto ocurrió en los años 70. (Palmer et ál, 1992, p. 45)

La monstruosidad de una transgresión como el incesto en la visión del mundo bribri refleja el principio de proporcionalidad entre la causa y el efecto, a la manera en que sucede todo en el sũwõ'. Sus textos se han transmitido de generación en generación desde tiempos inmemoriales y constituyen la historia viva de la cultura. La tradición oral, así, es una praxis que incluye no solo el acto de transmitir, sino también la capacidad del narrador de revivir la historia de su pueblo; el narrador es un ser recreativo y creativo a la vez, capaz de dar su propia perspectiva y de revitalizar la tradición oral a través de su discurso. Como señala Richard Bauman (1992, p. 126), la tradición oral deja de ser simplemente un género antiguo que se transmite de generación en generación, para convertirse en lo que llama "tradicionalización", término con el que pone de manifiesto el carácter dinámico de la tradición oral y al cual define como una construcción simbólica mediante la cual la gente del presente establece conexiones con un pasado significativo y atribuye valor y autoridad a las formas culturales particulares.

\section{Notas}

1. En cuanto a la ortografía, solamente se ha sustituido, conforme a nuestra práctica actual, el subrayado de las vocales nasales ( $\underline{\mathrm{a}}, \underline{\mathrm{e}}, \underline{\mathrm{i}}, \underline{\mathrm{o}}, \underline{\mathrm{u}})$ por el diacrítico de nasalidad del Alfabeto Fonético Internacional: ã, ẽ, ̃̃, õ, ũ.

2. Francisco Pereira incluye en la publicación su propia traducción al español, la cual constituye en sí misma una versión bastante estilizada; he preferido utilizar una traducción más literal con el fin de hacer énfasis en ciertos elementos del texto original, los cuales destaco en negrita en ambas versiones.

3. Pereira traduce shakìbök como "lamprea gigante". Al investigar sobre el animal correspondiente en el mundo real (Hyperoartia, una clase de agnatos o peces sin mandíbula), no parece que existan lampreas al menos en las lagunas de la región de Talamanca. De acuerdo con otras fuentes, i.e. Palmer et ál., 1992; Alí García (comunicación personal), el mítico animal corresponde en este mundo a la sanguijuela (Annelida), la cual sí está documentada en la zona (e.g. Oceguera-Figueroa y Pacheco-Chaves, 2012). La confusión en la traducción puede deberse a que ambos animales tienen por boca una ventosa dentada con la cual se pegan de su huésped, le rompen la piel y le succionan la sangre.

\section{Bibliografía}

Bauman, R. (1992). Contextualization, tradition, and the dialogue of genres: Icelandic legends of the kraftskáld. Por A. Duranti y C. Goodwin (Eds.). Rethinking Context. (77-99). Cambridge: Cambridge University Press.

Código Penal. (2011). (26 ed.). San José: Investigaciones Jurídicas.

García-Segura, A. y Jaén, A. (1996). Ies sa' yilite: Los ojos del alma. San José: Centro Cultural Español/Agencia Española de Cooperación Internacional.

INEC. (2013). X Censo Nacional de Población y VI de Vivienda: Territorios Indígenas. [pdf.] http://www.inec.go.cr/ [Consulta 15 de setiembre de 2014].

Jara-Murillo, C. V. (2006). Estructura y textura en un texto tradicional bribri. Revista de Filología y Lingüística de la Universidad de Costa Rica. 32 (1), 157-209. 
Jara-Murillo, C. V. y García-Segura, A. (1997). Kó Késka. El lugar del tiempo. San José: Editorial de la Universidad de Costa Rica / Comisión Costarricense de Cooperación con la UNESCO.

Jara-Murillo, C. V. y García-Segura, A. (2003). Diccionario de mitología bribri. San José: Editorial de la Universidad de Costa Rica.

Jara-Murillo, C. V. y García-Segura, A. (2008). Cargos tradicionales del pueblo bribri. Sĩo'tãmĩ, Óköm, Awá. San José: Instituto Costarricense de Electricidad / Instituto de Investigaciones Lingüísticas, UCR.

Oceguera-Figueroa, A. y Pacheco-Chaves, B. (2012). Registros de sanguijuelas de Costa Rica y clave para la identificación de las especies con redescripción de Cylicobdella costaricae. Revista Mexicana de Biodiversidad. 83, 946-957.

Palmer, P., Sánchez, J. y Mayorga, G. (1992). Vías de extinción, Vías de supervivencia. San José: Editorial de la Universidad de Costa Rica.

Pereira-Mora, F. (s.f. [1983]). Kũlũ̀. Tradición Oral Indígena Costarricense. 1 (3), 22-27.

Sánchez-Avendaño, C. (2013). Lenguas en peligro en Costa Rica: Vitalidad, documentación y descripción. Káñina, Revista de Artes y Letras de la Universidad de Costa Rica. 37 (1), 219-250.

Stone, D. (1961). Las tribus talamanqueñas de Costa Rica. San José: Museo Nacional de Costa Rica. 
